\title{
Effect of rare earth element Gd on the mechanical Properties of AZ91D
}

\author{
alloy \\ XIANG Yan ${ }^{1, a}$, LIANG $\operatorname{Jin}^{1, b}$ LIU Hong xia ${ }^{1, c}$, ZHANG Xiao lian ${ }^{1, d}$ \\ ( ${ }^{1}$ School of Chemistry and Chemical Engineering, Gannan Normal University, Gan zhou 341000, \\ Jiangxi, China)

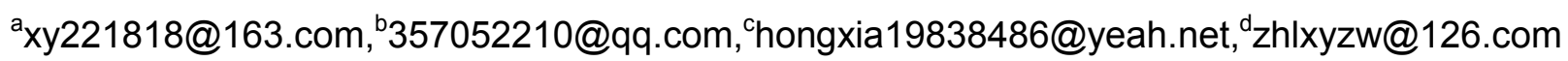

Keywords: AZ91D; Gd; master alloy; mechanical properties

Abstract: The magnesium alloys with rare earth element Gd were prepared by induction melting furnace. Influences of $\mathrm{Gd}$ on the microstructure and mechanical properties of AZ91D were investigated. The results showed that addition of Gd to AZ91D alloy could refine the microstructure including primary $\alpha-\mathrm{Mg}$ phase and eutectic $\beta-\mathrm{Mg}_{17} \mathrm{Al}_{12}$. The tensile properties were improved greatly with addition of Gd to AZ91D both at room temperature and elevated temperature. It was found that the excellent mechanical properties were obtained when the Gd content was 2 wt.\%. Inaddition, the fracture morphologies indicated that the AZ91D has the characteristics of a brittle fracture.

\section{Introduction}

Magnesium alloys are widely used as cast alloys, especially the AZ91 series. AZ91 alloys are interesting for transport applications such as automobile and aerospace construction, and 3C industries due to their low densities, high specific strength to stiffness ratio, good electromagnetic shielding characteristic, easily machined and good casting property. It is found that the mechanical properties of AZ91D are improved by the rare earth elements and the application field are expanded. Recently, a large number of researches have been conducted on the mechanical properties of AZ91 affected by the rare earth elements such as $\mathrm{Y}, \mathrm{La}, \mathrm{Ce}, \mathrm{Nd}$ and mischmetal. Unfortunately, there are few literatures repored on the influence of $\mathrm{Gd}$ on mechanical properties of AZ91D. The element $\mathrm{Gd}$ has a hexagonal close-packed crystal structure, the lattice constant are $\mathrm{a}=3.634 \mathrm{~nm}$ and $\mathrm{e}=5.781 \mathrm{~nm}$, the density is $7.87 \mathrm{~g} / \mathrm{cm}^{3}$, the melting point is $1313^{\circ} \mathrm{C}$ and the boiling point is $3266^{\circ} \mathrm{C}$. The solid solubility limit of $\mathrm{Gd}$ in $\mathrm{Mg}$ is $23.5 \mathrm{wt} . \%$ at eutectic temperature, and decreased significantly as the temperature decreasing. Gd as one of the yttrium group of rare earth elements has attracted more and more attention by many research workers in recent years

In the present paper, the effects of Gd on the mechanical properties of AZ91D were investigated. The results obtained in this study will develop theoretical and experimental basis for achieving the low cost and high property magnesium alloys, and widespreading their application in automobile, $3 \mathrm{C}$, the aerospace industry and so on.

\section{Experiment}

Raw materials: AZ91D alloy was prepared by FT Alloy Co. Itd, Gd was added as the form of a $\mathrm{Mg}-25 \% \mathrm{Gd}$ master alloy which was proudced by fused salt electrolysis process.

Experimental procedures: The furnace with the graphite crucible was preheated to $300^{\circ} \mathrm{C}$ and lasted for 2 hours. The AZ91D alloy was added and the temperature was increased to $680^{\circ} \mathrm{C}$ at a 
constant speed. After that, the master alloy $\mathrm{Mg}-25 \% \mathrm{Gd}$ was added when the AZ91D alloy was melted, then the temperature was increased to $720^{\circ} \mathrm{C}$. The refining agent was added, and $1 \mathrm{~h}$ was allowed for melt purified and homogenization. The melt was casted with the metal mold at the pouring temperature of $680{ }^{\circ} \mathrm{C}$. The melt was protected by the mixed gas of Nitrogen and R134a gas to prevent from igniting and oxidating during the procedures.

The chemical composition of the alloys was tested by ICP and the results are shown in Table. 1. The mechanical properties of $\mathrm{Mg}$ alloys were tested at the room temperature $\left(25^{\circ} \mathrm{C}\right)$ and high temperature $\left(150^{\circ} \mathrm{C}\right)$ under the condition of $1 \mathrm{~mm} / \mathrm{min}$ by WDW-200 electron-tensile tester, respectively. The tensile strength and elongation were investigated in present paper. The fracture morphologies were observed and analyzed by SEM, and the rare earth rich phase formed during the casting was determined by XRD.

Table 1 Chemical composition of the alloys (wt.\%)

\begin{tabular}{ccccccc}
\hline $\begin{array}{c}\text { Sample } \\
\text { Number }\end{array}$ & $\mathrm{Mg}$ & $\mathrm{Al}$ & $\mathrm{Zn}$ & $\mathrm{Mn}$ & $\mathrm{Gd}$ & Gd addition \\
\hline D1 & Balance & 8.681 & 0.816 & 0.336 & 0.438 & 0.5 \\
D2 & Balance & 8.457 & 0.703 & 0.378 & 0.884 & 1.0 \\
D3 & Balance & 8.622 & 0.760 & 0.254 & 1.365 & 1.5 \\
D4 & Balance & 8.801 & 0.595 & 0.301 & 1.951 & 2.0 \\
D5 & Balance & 8.565 & 0.623 & 0.390 & 2.333 & 2.5 \\
D0 & Balance & 9.058 & 0.795 & 0.374 & - & 0 \\
\hline
\end{tabular}

\section{Results and Discussion}

Mechanical Properties of AZ91D with the addition of Gd. The mechanical properties of $\mathrm{Mg}$ alloys, such as the tensile strength and elongation, were tested at the room temperature $\left(25^{\circ} \mathrm{C}\right)$ and high temperature $\left(150^{\circ} \mathrm{C}\right)$ under the condition of $1 \mathrm{~mm} / \mathrm{min}$, respectively. The results are shown in Fig. 1 and Fig.2. It can be seen that the mechanical properties of AZ91D alloys are greatly improved both at the room temperature and high temperature with the addition of rare earth element $\mathrm{Gd}$. The results show that the tensile strength is increased to $22 \%$ and the elongation can be increased to $32 \%$ at room temperature, and the tensile strength is increased to $17 \%$ and the elongation can be increased to $25 \%$ at high temperature. The tensile strength was first increased, and then decreased with the Gd increasing, as shown in Fig. 1. The optimum performance of $\mathrm{Mg}$ alloys was obtained when the content of $\mathrm{Gd}$ is $2 \mathrm{wt} . \%$, and the tensile strength was gradually decreased with the Gd increasing. The elongation was decreased first, then riseed and finally decreased again at room temperature, while it was decreased first and then increased at high temperature. The elongation of alloys was reached to the maximum when the content of $2 \% \mathrm{Gd}$, and it was decreased with the $\mathrm{Gd}$ increasing. Therefore, the mechanical properties of AZ91D were greatly improved with the addition of $2 \mathrm{wt} . \%$ content of $\mathrm{Gd}$ under the condition of room temperature and high temperature. 


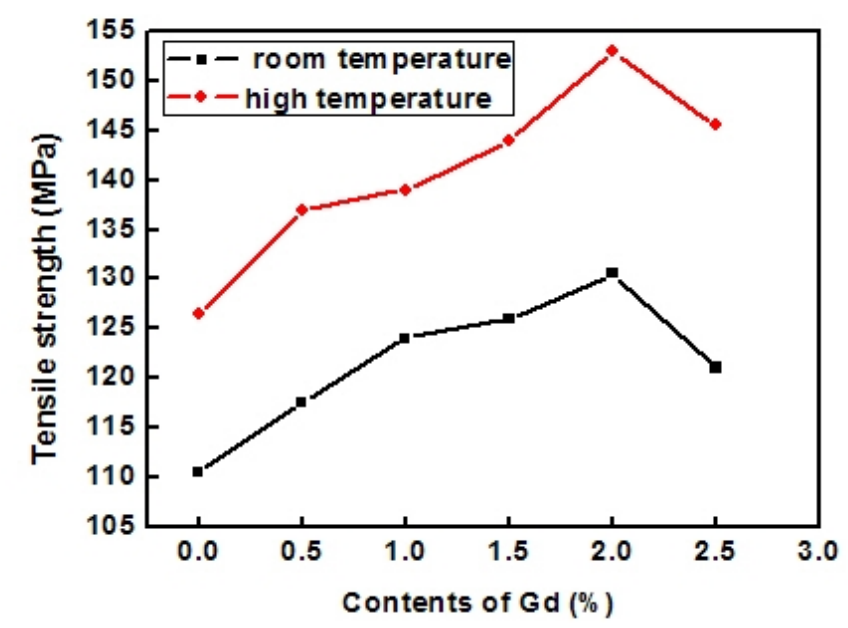

Fig. 1 The tensile strength of AZ91D with different content of Gd

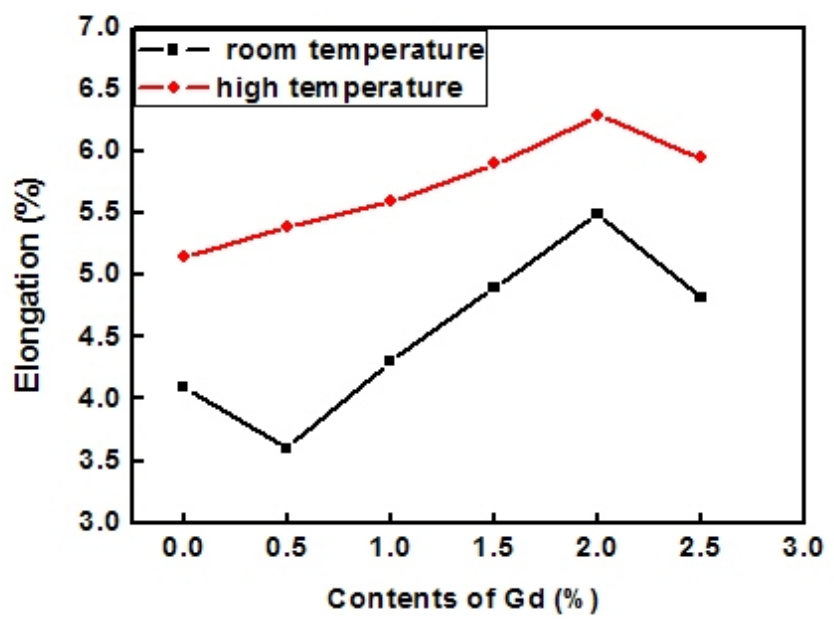

Fig.2 The elongation of AZ91D with different content of Gd

Structures of AZ91D with the addition of Gd. The phase composition of AZ91D with the addition of rare earth element $\mathrm{Gd}$ was observed By XRD. The primary $\alpha-\mathrm{Mg}$ solid solution and the eutectic phase $\beta-\mathrm{Mg}_{17} \mathrm{Al}_{12}$ were observed in $\mathrm{Mg}$ alloys. Inaddition, the rare earth rich phase $\mathrm{Al}_{2} \mathrm{Gd}$ was determined when the Gd was added. The results showed that the addition of Gd to AZ91D alloy could refine the microstructures, especially for eutectic phase $\beta-\mathrm{Mg}_{17} \mathrm{Al}_{12}$. The volume of $\beta-\mathrm{Mg}_{17} \mathrm{Al}_{12}$ decreased and the morphologies refined with the addition of rare earth element $\mathrm{Gd}$, as shown in Fig. 3. In addition, according to the Hall-Petch formula:

$$
\sigma=\sigma_{0}+k d^{-1 / 2}
$$

Where $\sigma$ is the strength, $\sigma_{0}$ is the resistance of dislocation motion, $k$ is the constant, and $d$ is the diameter of grain.

Eq. 1indicates that the strength of the alloy is increased with the grain size $d$ decreasing. In this study, the microstructure and the grain size of AZ91D were refined with the addition of the rare earth element $\mathrm{Gd}$, and the tensile strength was also increased with the addition of $\mathrm{Gd}$, which was consistent with that of the prediction from Eq. 1. 


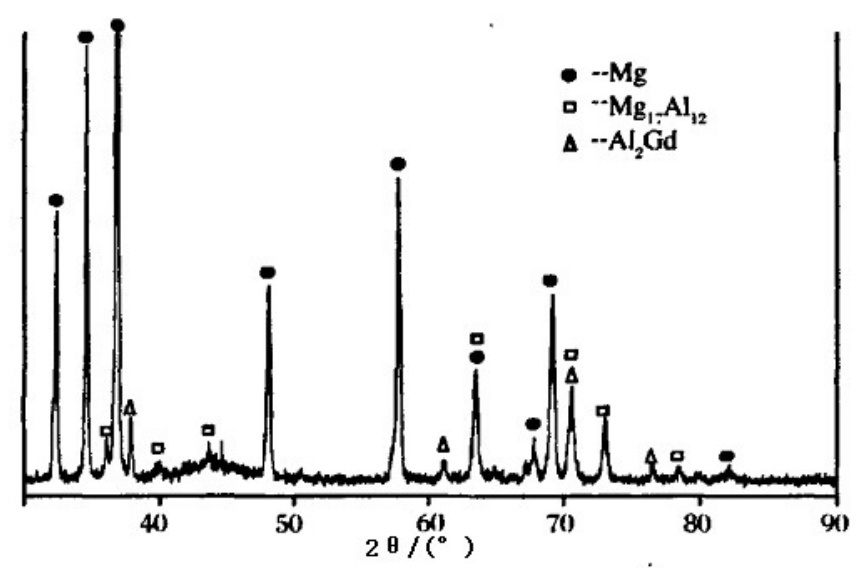

Fig.3 The XRD results of AZ91D alloy with the addition of Gd

Fig. 4 shows the fracture morphologies of alloy D0 and D4, which were tested at the room temperature. It can be seen that the D0 magnesium alloy appears crystalline state, the fracture is even and agleam. The fracture morphologies of D4 magnesium alloy which added Gd appears crystalline state also, and with a little cleavage fracture, which are belong to brittle fracture.
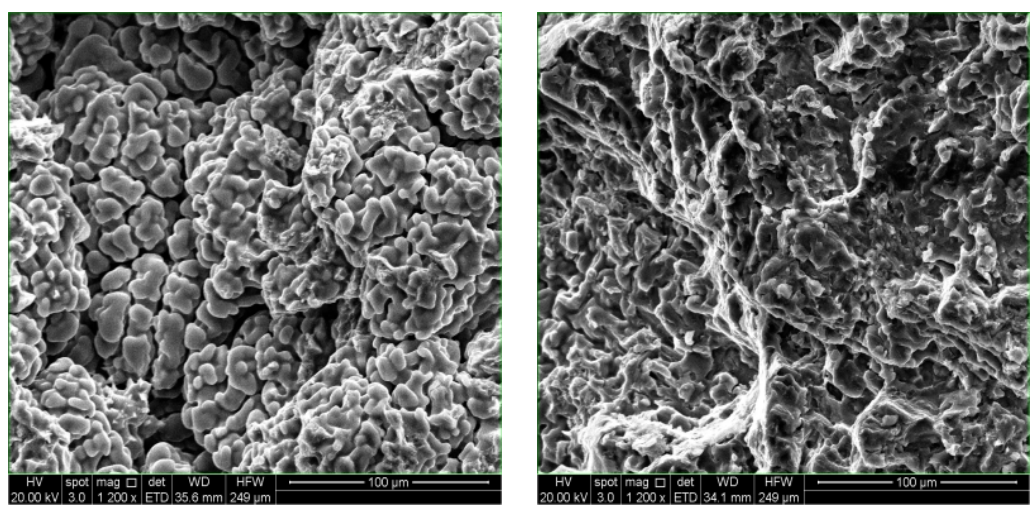

Fig.4 The fracture morphologies of alloy tested at room temperature

(a) D0

(b) $\mathrm{D} 4$

\section{Conclusions}

1) The mechanical properties of AZ91D were greatly improved with the addition of rare earth element Gd.

2) At room temperature, the tensile strength of AZ91D with Gd is increased by $22 \%$ and the elongation can be increased by $32 \%$; at high temperature, the tensile strength and elongation could enhance $17 \%$ and $25 \%$, respectively.

3) The optimum performance of $\mathrm{Mg}$ alloys was obtained when the content of Gd is $2 \mathrm{wt} . \%$,

4) The fracture type of AZ91D magnesium alloy is brittle fracture.

\section{Acknowledgements}

This work was financially supported by the National Natural Science Foundation of China (51464002) and Science and Technology Project of Jiangxi Municipal Education Department (KJLD14077). 


\section{References}

[1] T. Ding-xiang, L. Yu-jiu. Rare Earth Metal Material. 1(2011) 416-419.

[2] Mustafa Kemal Kulekci. Int J Adv Manuf Technol. 2008, 39:851-865.

[3] L.Zhong, Z.Jian, S.Zhi-mei et al. Chin Sci Bull, 2013, 58(1): 98 102.

[4] S.Kai, W.Ri-chu, P.chao-qun etal. Corr Sci and Prot Tec, 2012, 24(2): 81 85.

[5] Hossein Bayani, Ehsan Saebnoori. Journal of Earths, 2009, 27(2): 255 258.

[6] T Guo-dong, L. Hai-feng, L. Yao-hui. Trans. Nonferrous Met.Soc.China, 2010(20): 336 340.

[7] L.Ping. Nonferrous Metals, 2008, 60(1): 22 24.

[8] W. Xiao-qiang, L.An-quan,Z. Xing-yuan. Mater Rev, 2007, 21(5A): 389 394.

[9] Z.Qing, L.An-quan, W. Jiu-ba. New Tec and New Pro, 2006, (6): 66 67.

[10] Z.Wei-chao, L.Shuang-shou, Y.Bin. Acta Metallurgica Sinica, 2006, 42(8): 835 842.

[11] S.Ting. Hot Working Technology, 2013, 42(8): 69 71.

[12] C.Fu-rong, L.Shi-hui,G.Feng et al.Foundry Technology, 2009,30(2):203 206.

[13] W. Jun, W. Limin. Journal of Materials Engineering and Performance, 2008, 17(5): 725 729.

[14] M. Sumida, S. Jung, T. Okane. Materials Transactions, 2009, 50(5): 1161 1168. 